\title{
Gas-Solid Reaction Properties of Fluorine Compounds and Solid Adsorbents for Off-Gas Treatment from Semiconductor Facility
}

\author{
Shinji Yasui, ${ }^{1}$ Tadashi Shojo, ${ }^{2}$ Goichi Inoue, ${ }^{2}$ Kunihiko Koike, ${ }^{2}$ \\ Akihiro Takeuchi, ${ }^{3}$ and Yoshio Iwasa ${ }^{3}$ \\ ${ }^{1}$ Nagoya Institute of Technology, Gokiso-cho, Showa-ku, Nagoya 466-8555, Japan \\ ${ }^{2}$ Iwatani Corporation, 4-5-1 Katsube, Moriyama-shi, Shiga 524-0041, Japan \\ ${ }^{3}$ Chubu Electric Power Co., Inc., 20-1 Kitasekiyama, Odaka-cho, Midori-ku, Nagoya 459-8522, Japan \\ Correspondence should be addressed to Shinji Yasui, yasui.shinji@nitech.ac.jp
}

Received 23 March 2012; Accepted 19 June 2012

Academic Editor: Annabelle Couvert

Copyright (c) 2012 Shinji Yasui et al. This is an open access article distributed under the Creative Commons Attribution License, which permits unrestricted use, distribution, and reproduction in any medium, provided the original work is properly cited.

\begin{abstract}
We have been developing a new dry-type off-gas treatment system for recycling fluorine from perfluoro compounds present in off-gases from the semiconductor industry. The feature of this system is to adsorb the fluorine compounds in the exhaust gases from the decomposition furnace by using two types of solid adsorbents: the calcium carbonate in the upper layer adsorbs HF and converts it to $\mathrm{CaF}_{2}$, and the sodium bicarbonate in the lower layer adsorbs $\mathrm{HF}$ and $\mathrm{SiF}_{4}$ and converts them to $\mathrm{Na}_{2} \mathrm{SiF}_{6}$. This paper describes the fluorine compound adsorption properties of both the solid adsorbents—calcium carbonate and the sodium compound-for the optimal design of the fixation furnace. An analysis of the gas-solid reaction rate was performed from the experimental results of the breakthrough curve by using a fixed-bed reaction model, and the reaction rate constants and adsorption capacity were obtained for achieving an optimal process design.
\end{abstract}

\section{Introduction}

Fluorocarbons and perfluoro compounds (PFCs) contribute to global warming and are used in large quantities in the semiconductor industry, which must reduce the emission of these gases to the atmosphere in order to achieve the requirements of the Kyoto Protocol. In the semiconductor industry, voluntary reduction goals for PFCs were set at the World Semiconductor Council held in April 1999 and ongoing reduction efforts have been made. However, since hydrofluorocarbons (HFCs) and PFCs are used in critical processes, including chamber cleaning and etching during the manufacturing of semiconductors such as LCDs and solar panels, the consumption of these chemicals increases every year. Therefore, in spite of the reduction efforts, the emission of fluorocarbons and PFCs has increased in recent years.

The technology for the treatment of PFCs, which has been supplied in the semiconductor industries as an inexpensive process, is a combination of combustion to decompose PFCs into acid components such as HF and scrubbing to neutralize the acid components [1]. However, because the combustion method has a low decomposition ratio and the treatment of the resultant wastewater has a high energy load, a new dry treatment technology is desirable. Consequently, we are developing a new dry-type treatment technology for PFCs that consists of an electric furnace for decomposition of the PFCs and a dry-fixation furnace for adsorption of the acid components, which enables fluorine recycling. Fluorine is a precious resource for Japan, which imports most of its fluorine from China or Mexico [2]. This paper describes the details of the treatment process, the gas-solid reaction properties of fluorine compounds, and solid adsorbents in the dry-fixation furnace of the fluorine recycling system.

\section{Dry-Type Treatment System}

The processing flow of the treatment system being developed is shown in Figure 1. The treatment system is divided into three parts. In the semiconductor industry, silane $\left(\mathrm{SiH}_{4}\right)$ is used for $\mathrm{Si}$ deposition, and $\mathrm{NF}_{3}$ is mainly used as the chamber-cleaning gas. These gases are used alternately in the 


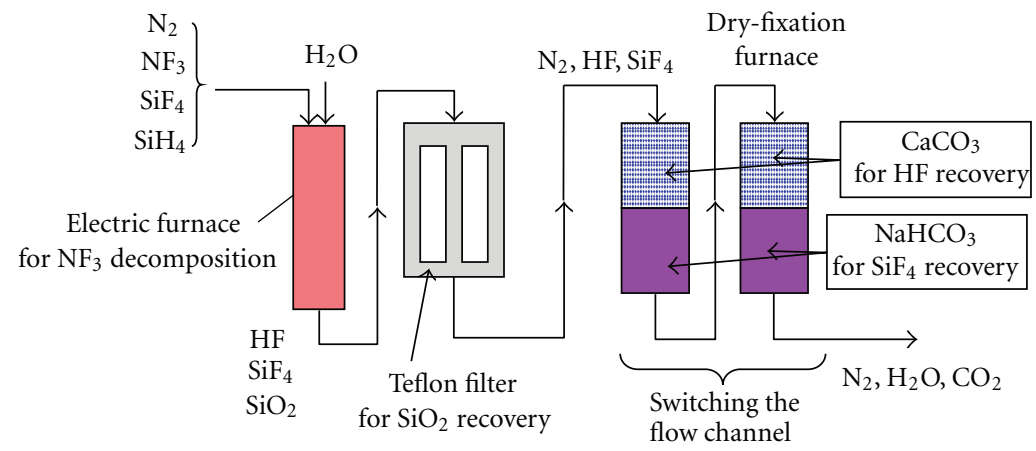

FIgURE 1: Schematic of the dry-type gas treatment system.

chamber; that is, the exhaust gases from the process chamber include $\mathrm{SiH}_{4}, \mathrm{NF}_{3}$, and $\mathrm{SiF}_{4}$ diluted with $\mathrm{N}_{2}$ through the vacuum pump. Initially in the treatment process, $\mathrm{NF}_{3}$ and $\mathrm{SiH}_{4}$ are decomposed in the electric furnace to form HF, $\mathrm{SiF}_{4}$, and $\mathrm{SiO}_{x}$. The $\mathrm{SiO}_{x}$ powder is then removed using a Teflon filter, and the remaining $\mathrm{HF}$ and $\mathrm{SiF}_{4}$ are adsorbed by solid adsorbents in the subsequent dry-fixation furnace. The dry-fixation furnace is a switching system with two columns, each filled with an upper layer of calcium carbonate and a lower layer of sodium bicarbonate; the calcium carbonate in the upper layer adsorbs $\mathrm{HF}$ and converts it to $\mathrm{CaF}_{2}$ and the sodium bicarbonate in the lower layer adsorbs $\mathrm{HF}$ and $\mathrm{SiF}_{4}$ to convert them to $\mathrm{Na}_{2} \mathrm{SiF}_{6}$. These chemical reactions are shown as follows:

$$
\begin{gathered}
2 \mathrm{HF}+\mathrm{CaCO}_{3} \longrightarrow \mathrm{CaF}_{2}+\mathrm{H}_{2} \mathrm{O}+\mathrm{CO}_{2} \\
\mathrm{HF}+\mathrm{NaHCO}_{3} \longrightarrow \mathrm{NaF}+\mathrm{H}_{2} \mathrm{O}+\mathrm{CO}_{2} \\
\mathrm{SiF}_{4}+2 \mathrm{HF}+2 \mathrm{NaHCO}_{3} \longrightarrow \mathrm{Na}_{2} \mathrm{SiF}_{6}+2 \mathrm{H}_{2} \mathrm{O} \\
+2 \mathrm{CO}_{2}
\end{gathered}
$$

The vapor and $\mathrm{CO}_{2}$ byproducts do not require further treatment. Because the Teflon filters have to be processed at low temperatures, less than $200^{\circ} \mathrm{C}$, it is desirable to process the gas-solid reaction of each adsorbent at a low temperature of $150^{\circ} \mathrm{C}$ for negligible reheating system. The treatment flow rate in the developing system is $300 \mathrm{~L} / \mathrm{min}\left(3 \% \mathrm{NF}_{3}\right.$ and $0.5 \%$ $\mathrm{SiH}_{4}$ in $\mathrm{N}_{2}$ ) from emissions from the three chambers of the semiconductor-processing device.

The purpose of the dry-fixation furnace in this system is to generate high-purity calcium fluoride during the offgas treatment. The reaction properties of each adsorbent are shown in Figure 2. The role of the sodium bicarbonate is to adsorb any $\mathrm{HF}$ gas breakthrough from the $\mathrm{CaCO}_{3}$ layer by converting it to high-purity calcium fluoride and also to adsorb $\mathrm{SiF}_{4}$ gas during the treatment process, because $\mathrm{SiF}_{4}$ gas does not react with $\mathrm{CaCO}_{3}$ at a low temperature of $150^{\circ} \mathrm{C}$.

\section{Fixed-Bed Reaction Model}

In order to achieve the optimal design of the reaction vessel of the dry-fixation furnace, we investigated the reaction property of $\mathrm{HF}$ gas and the solid adsorbent of $\mathrm{CaCO}_{3}$. We used the fixed-bed reaction model for analyzing this reaction property. By assuming that the distribution of the HF gas concentration as the gas moved from inlet to outlet in the $\mathrm{CaCO}_{3}$ layer remained constant, the reaction rate of $\mathrm{HF}$ and $\mathrm{CaCO}_{3}$ in the fixed-bed furnace can be estimated from the differential time of the HF concentration in the outlet gas breakthrough from the fixed-bed furnace.

Under the isothermal conditions in the fixed-bed furnace and by negligible volume change of the reactive gases, the mass balance of the HF component at the cross-sectional area in the fixed-bed furnace is given by the following equation using the symbols defined in Figure 3:

$$
v \frac{\partial C_{\mathrm{HF}}}{\partial x}+\varepsilon \frac{\partial C_{\mathrm{HF}}}{\partial t}=-\frac{\partial \eta}{\partial t} .
$$

The reaction zone of the $\mathrm{HF}$ gas and $\mathrm{CaCO}_{3}$ is formed in the fixed-bed furnace, as shown in Figure 4, and the zone is moved forward to the outlet at the constant velocity of $u_{S}$. Under these conditions, the HF gas flowing into the furnace accumulates in the solid adsorbent, and the reaction zone is moved only by the amount of the accumulation. The mass balance at this time is represented by the following equation:

$$
v \cdot C_{\mathrm{HF}}^{0}=u_{S} \cdot \eta^{0} .
$$

In the steady state, the time change of the molar concentration of HF in the fixed-bed furnace is determined by the moving velocity of the HF concentration curve with a constant shape, and the relationship between them is represented by the following equation:

$$
\frac{\partial C_{\mathrm{HF}}}{\partial t}=-u_{\mathrm{S}} \frac{\partial C_{\mathrm{HF}}}{\partial x} .
$$

The following equation is obtained from (4), (5), and (6):

$$
\left(\varepsilon-\frac{\eta^{0}}{C_{\mathrm{HF}}^{0}}\right) \frac{\partial C_{\mathrm{HF}}}{\partial t}=-\frac{\partial \eta}{\partial t} .
$$

The following relationship is satisfied in our fixed-bed furnace:

$$
\varepsilon \ll \frac{\eta^{0}}{C_{\mathrm{HF}}}
$$




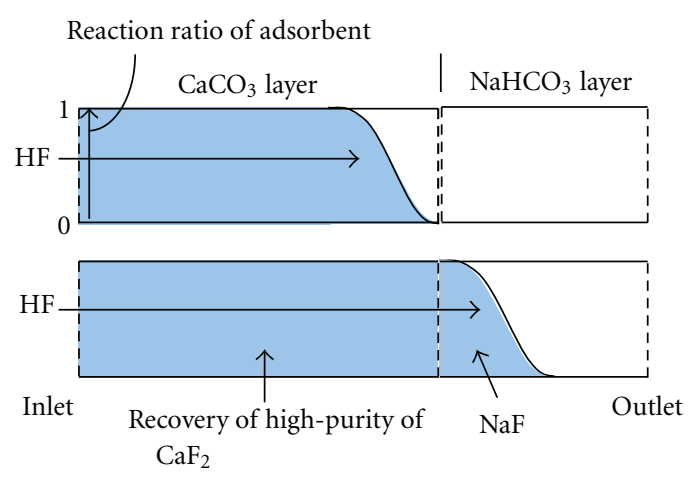

(a) Reaction property of $\mathrm{CaCo}_{3}$

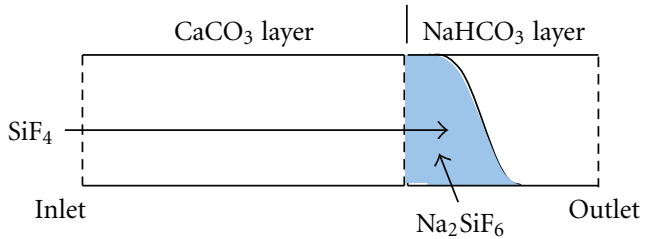

(b) Reaction property of $\mathrm{NaHCO}_{3}$

FIgURE 2: Schematic of the dry-type gas treatment system.

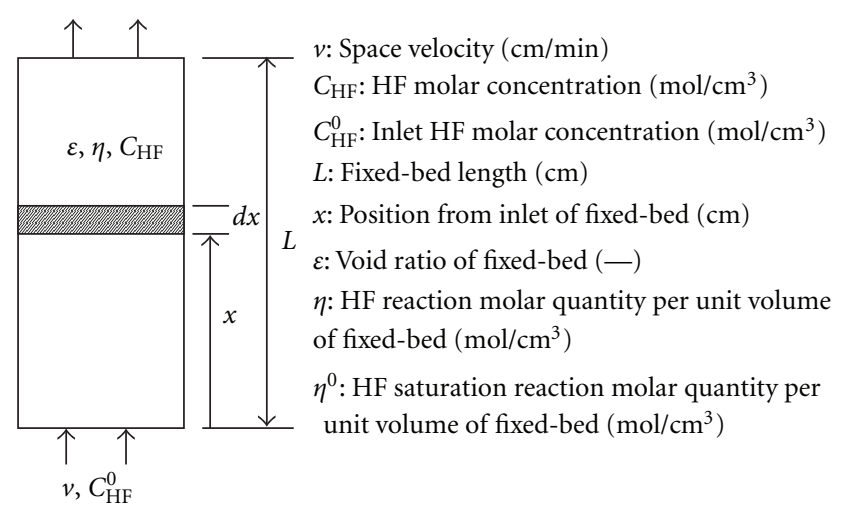

Figure 3: Description of material balance of fixed-bed reaction furnace.

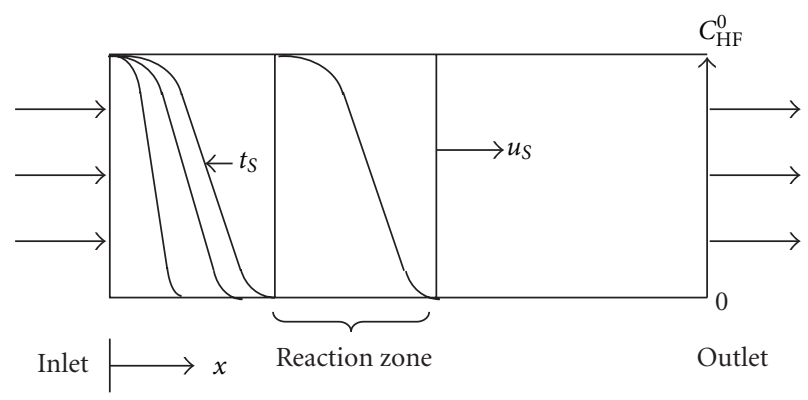

FIGURE 4: Inside phenomenon on the fixed-bed furnace.

From (7) and (8), the relationship between HF molar adsorption quantity per unit volume of fixed-bed furnace and the HF molar concentration can be expressed by the following equation:

$$
\frac{\partial\left(C_{\mathrm{HF}} / C_{\mathrm{HF}}^{0}\right)}{\partial t}=\frac{\partial\left(\eta / \eta^{0}\right)}{\partial t} .
$$

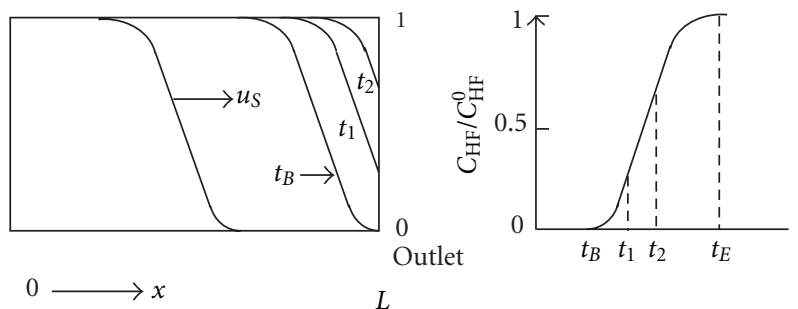

Figure 5: Breakthrough curve as compared with inside phenomenon on fixed-bed reactor.

By evaluating this relationship at the outlet part of the fixedbed furnace, this equation can be expressed as ordinary differential equations:

$$
\frac{d\left(C_{\mathrm{HF}} / C_{\mathrm{HF}}^{0}\right)}{d t}=\frac{d\left(\eta / \eta^{0}\right)}{d t} .
$$

Therefore, HF molar adsorption quantity per unit volume at the outlet of the fixed-bed furnace and the HF gas concentration in the gas exhausted from the fixed-bed furnace obtained by the experiments show the same changes for the reaction time, as shown in Figure 5. The ratio $\eta / \eta^{0}$ is the normalized fluoride ratio of $\mathrm{CaCO}_{3}$. The fluoride ratio does not change even if the saturation amount is changed from the per unit volume to the per unit weight, so the following equation is obtained:

$$
\frac{\eta}{\eta^{0}}=\frac{\eta_{g}}{\eta_{g}^{0}}
$$

where $\eta_{g}$ is the HF molar adsorption quantity per unit weight and $\eta_{g}^{0}$ is the HF adsorption capacity per unit weight of $\mathrm{CaCO}_{3}$. Finally, the following relationship can be obtained from (10) and (11):

$$
\frac{d\left(\eta / \eta^{0}\right)}{d t}=\frac{d\left(\eta_{g} / \eta_{g}^{0}\right)}{d t} .
$$


TABLE 1: Experimental conditions for the gas-solid reaction.

\begin{tabular}{lcc}
\hline & Practical system & Experimental conditions \\
\hline Processing flow rate & $400 \mathrm{~L} / \mathrm{min}$ & $1.6 \mathrm{~L} / \mathrm{min}$ \\
Inner diameter & $45 \mathrm{~cm}$ & $2.8 \mathrm{~cm}$ \\
Superficial velocity & $6 \mathrm{~cm} / \mathrm{s}$ & $6 \mathrm{~cm} / \mathrm{s}$ \\
L/D ratio & 1.2 & 1.2 \\
$\mathrm{CaCO}_{3}$ weight & $120 \mathrm{~kg}$ & $31 \mathrm{~g}$ \\
Space velocity (SV) & $400 \mathrm{~h}^{-1}$ & $6700 \mathrm{~h}^{-1}$ \\
Adsorbent size & $1 \sim 2 \mathrm{~mm}, 2 \sim 5 \mathrm{~mm}$ & $1 \sim 2 \mathrm{~mm}, 2 \sim 5 \mathrm{~mm}$ \\
Fixation temperature & $150^{\circ} \mathrm{C}$ & $150^{\circ} \mathrm{C}$ \\
\hline
\end{tabular}

In this research, the reaction rate of $\mathrm{HF}$ gas and the solid adsorbent $\mathrm{CaCO}_{3}$ was evaluated by the differential value of the breakthrough curve of $\mathrm{HF}$ concentration in the exhaust gases obtained by the fundamental experiments. This fixed-bed reaction model was used in the analysis of the desulfurization catalyst quality $[3,4]$.

\section{HF Breakthrough Properties of $\mathrm{CaCO}_{3}$}

In our previous studies, the reaction rates of $\mathrm{HF}$ gas and the solid adsorbent $\mathrm{CaCO}_{3}$ were investigated in the fundamental experiments for the purpose of the recovering fluoride from the waste fluorocarbons $[5,6]$. In these studies, the reaction conditions of $\mathrm{HF}$ gas concentration were very high, 35\%$60 \%$. In a semiconductor factory, the concentration of the cleaning gas $\mathrm{NF}_{3}$ in the off-gas is less than about $5 \%$ at most, so the HF concentration in the exhaust gases from the electric decomposition furnace is assumed to be less than about $10 \%$. Therefore, the reaction rate of $\mathrm{HF}$ and $\mathrm{CaCO}_{3}$ was investigated in the low HF concentration conditions.

4.1. Experimental Conditions and Method. The important parameters for the design of reactors for gas-solid reactions are the particle size of the solid adsorbents, reaction temperature, and superficial velocity. The experimental conditions are consistent with the design specifications of these parameters for a practical system. The design specification and the experimental parameters are shown in Table 1.

The experiment flow is shown in Figure 6. The reaction gas, including $\mathrm{HF}$ gas, was obtained by thermal decomposition of HFC134a $\left(\mathrm{C}_{2} \mathrm{H}_{2} \mathrm{~F}_{4}\right)$ with water vapor and diluted at the entrance of the fixed-bed reaction furnace. The fixedbed reactor filled with calcium carbonate is made of stainless steel, which is heated uniformly in a vertical electric furnace. The temperature of the vertical electric furnace was set at $150^{\circ} \mathrm{C}$. HF gas concentrations of $1 \%, 5 \%$, and $10 \%$ and $\mathrm{CaCO}_{3}$ grain sizes of $1-2 \mathrm{~mm}$ and $2-5 \mathrm{~mm}$ were investigated. The breakthrough properties for each experimental condition were investigated by measuring the concentration of $\mathrm{F}$ ions in the impinger. The concentration of $\mathrm{F}$ ions was measured by using a $\mathrm{F}^{-}$ion sensor and ion chromatograph. The experimental conditions are summarized in Table 2.

4.2. Experimental Results. The results of the breakthrough properties are shown in Figure 7. The HF concentration in the off-gas from the fixed-bed reactor increased gradually after the moment of breakthrough and finally reached the initial concentration at the entrance of the fixed-bed reactor. The results shown in the vertical axis in Figure 7 were normalized by the initial HF concentration at the entrance.

The elapsed time from the breakthrough point to the complete breakthrough time $\left(C_{\mathrm{HF}} / C_{\mathrm{HF}}^{0}=1\right)$ increased under low HF concentration conditions. For a fixed-bed reactor, the differential of the breakthrough curve $\left(d\left(C_{\mathrm{HF}} / C_{\mathrm{HF}}^{0}\right) / d t\right)$ can be regarded as equal to the reaction rate $(d X / d t)$ of the $\mathrm{CaCO}_{3}$ filling the outside edge of the fixed-bed reactor:

$$
X=\frac{C_{\mathrm{HF}}}{C_{\mathrm{HF}}^{0}}
$$

where $X$ is the reaction ratio of $\mathrm{CaCO}_{3}$. Therefore, the slopes of the breakthrough curves of these results were evaluated and plotted against the HF concentration at the slope points, as shown in Figure 8. From these results, the reaction rate of $\mathrm{CaCO}_{3}$ can be determined using a first-order reaction formula of the HF concentration.

The results of the reaction rates of $\mathrm{CaCO}_{3}$ were investigated using the gas-solid reaction model of a shrinking unreacted core system. The reaction rate of a shrinking unreacted core system is expressed using the following equation [7]:

$$
\frac{d X}{d t}=\frac{C_{\mathrm{HF}}}{f_{S}^{-1} \cdot(1-X)^{-2 / 3}+f_{p}^{-1} \cdot\left[(1-X)^{-1 / 3}-1\right]+f_{g}^{-1}}
$$

Here, $f_{S}$ is the rate constant for the particle surface chemical reaction, $f_{p}$ is the rate constant for diffusion through the product layer of a spherical particle, and $f_{g}$ is the rate constant for the external mass transport. By evaluating the results of Figure 8 using (14), the overall reaction rate of $\mathrm{CaCO}_{3}$ could be expressed in terms of the two rate constants: the rate constant for diffusion through the product layer $\left(f_{p}\right)$ and the rate constant for external mass transport $\left(f_{g}\right)$ as shown in Figure 9.

Evaluating the slope and the intercept of the straight lines in Figure 9, each rate constant was obtained as shown in Table 3.

By using each obtained rate constant, it was possible to calculate the elapsed time from the initial breakthrough point to the complete breakthrough point by setting the initial concentration of $\mathrm{HF}\left(C_{\mathrm{HF}}^{0}\right)$ and the reaction ratio of $\mathrm{CaCO}_{3}$ (e.g., 0.95). From this calculated time, the amount of $\mathrm{HF}$ gas leaking from the $\mathrm{CaCO}_{3}$ layer until the $\mathrm{CaCO}_{3}$ was converted into high-purity $\mathrm{CaF}_{2}$ was calculated from the treatment flow rate. This indicates the amount of HF gas that needs to be adsorbed in the subsequent $\mathrm{NaHCO}_{3}$ layer.

\section{5. $\mathrm{SiF}_{4}$ Adsorption Properties of Sodium-Based Adsorbents}

The purpose of the $\mathrm{NaHCO}_{3}$ layer is to adsorb the HF and $\mathrm{SiF}_{4}$ exhausted from the $\mathrm{CaCO}_{3}$ layer. To determine the amount of $\mathrm{NaHCO}_{3}$ needed, it is necessary to calculate 


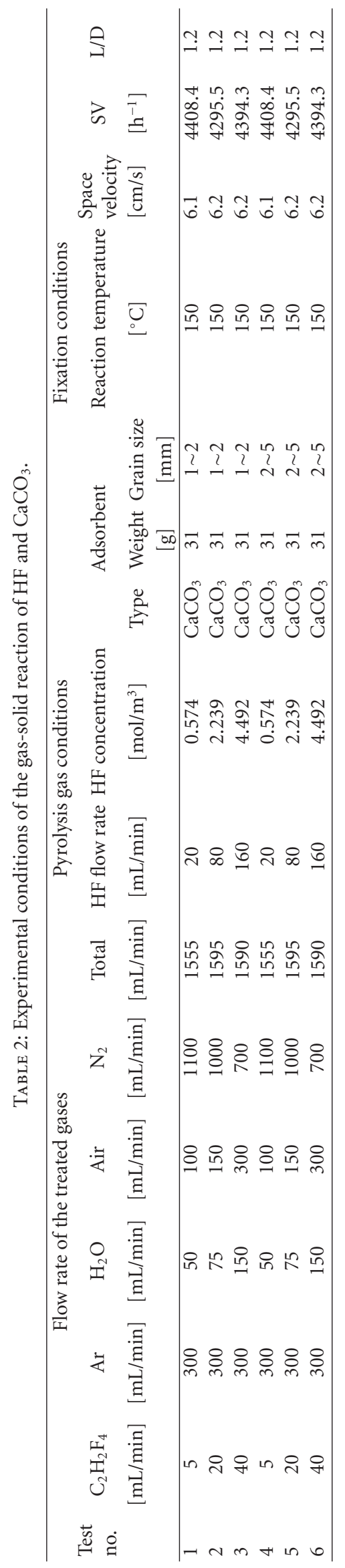




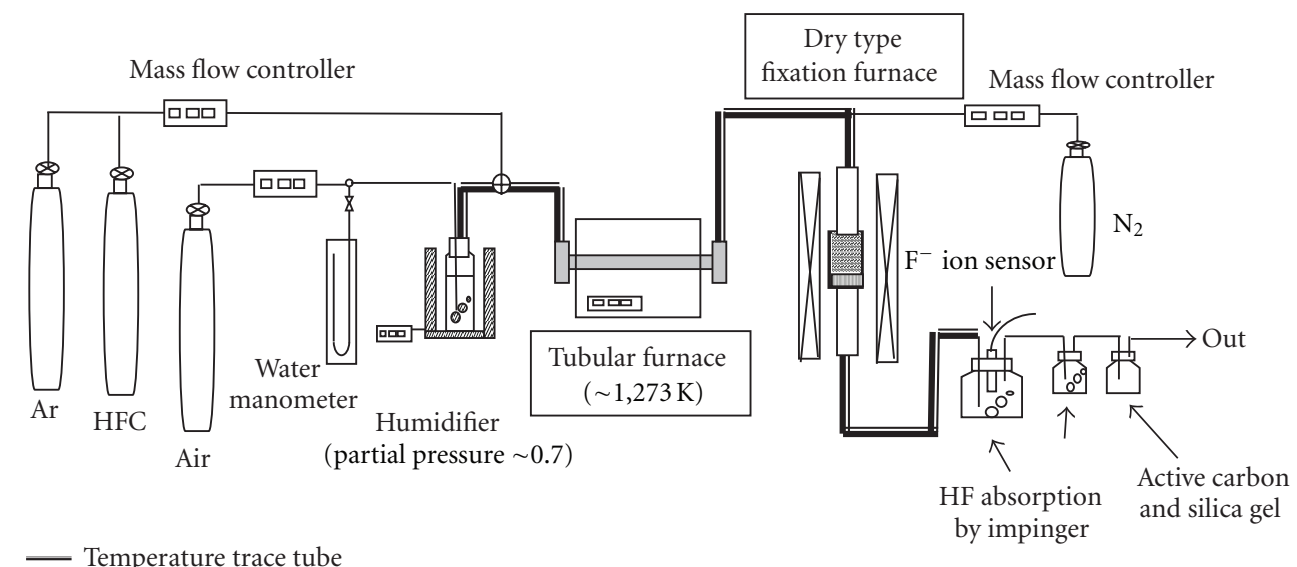

FIgURE 6: Experiment flow of the gas-solid reaction of $\mathrm{HF}$ and $\mathrm{CaCO}_{3}$.

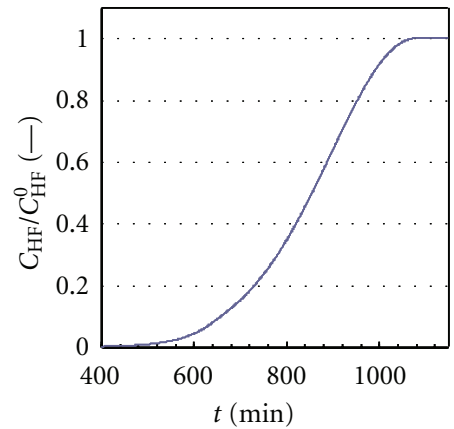

(a) HF conc.: $1 \%$

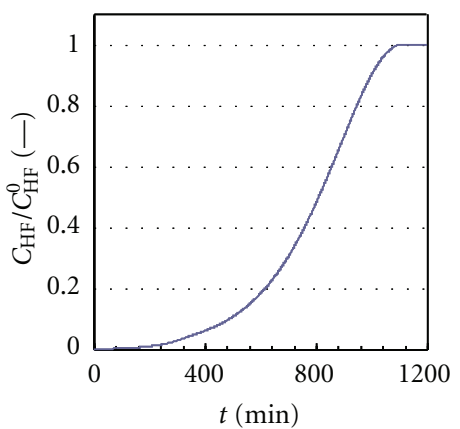

(a) HF conc.: $1 \%$

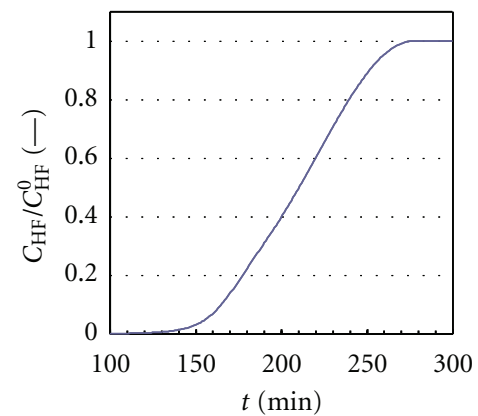

(b) HF conc.: $5 \%$

(A) Grain size: 1-2 mm

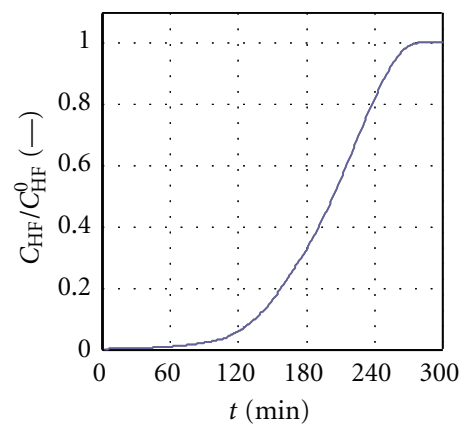

(b) HF conc.: $5 \%$

(B) Grain size: $2-5 \mathrm{~mm}$

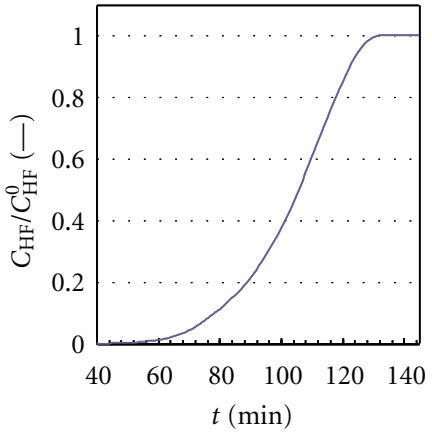

(c) HF conc.: $10 \%$

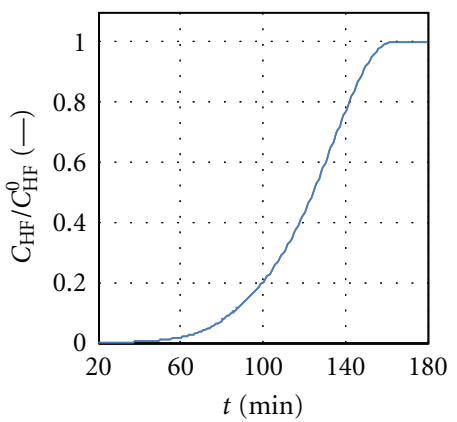

(c) HF conc.: $10 \%$

FIgURE 7: HF breakthrough properties of $\mathrm{CaCO}_{3}$.

the adsorption capacity of each gas. By the fundamental experiments in our studies, the amount of $\mathrm{NaHCO}_{3}$ needed for $\mathrm{HF}$ adsorption was confirmed to supply an equimolar amount of $\mathrm{HF}$ leaked from the $\mathrm{CaCO}_{3}$ layer because the reaction of $\mathrm{NaHCO}_{3}$ and $\mathrm{HF}$ at $150^{\circ} \mathrm{C}$ generate not only $\mathrm{NaF}$ and $\mathrm{NaHF}_{2}$ but also HF can be completely adsorbed by an equimolar amount of $\mathrm{NaHCO}_{3}$. Therefore, this section describes the results of the experiments for examination of the adsorption capacity of $\mathrm{SiF}_{4}$.
5.1. Experimental Conditions and Method. The experimental flow is shown in Figure 10. At first, HF was generated by thermal decomposition of HFC134a $\left(\mathrm{C}_{2} \mathrm{H}_{2} \mathrm{~F}_{4}\right)$ with water vapor and air; $\mathrm{SiF}_{4}$ was generated by the reaction of the HF and pieces of quartz. Then, these reaction gases were introduced into the fixed-bed furnace with $\mathrm{N}_{2}$ dilution gas to establish the $\mathrm{SiF}_{4}$ concentration and then reacted with sodium-based adsorbents in the furnace. We used two types of sodium-based adsorbents: $\mathrm{NaHCO}_{3}$ and $\mathrm{NaF}$. $\mathrm{NaF}$ was 


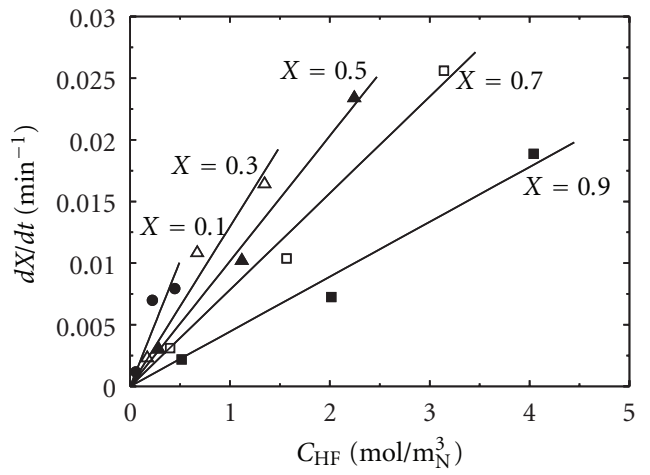

(a) Grain size: 1-2 mm

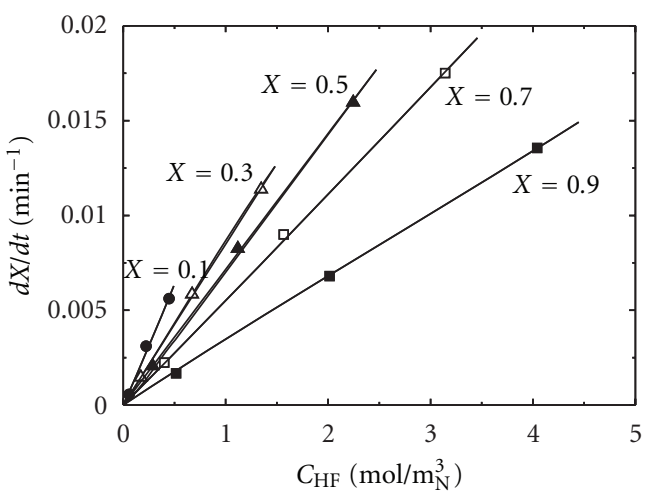

(b) Grain size: $2-5 \mathrm{~mm}$

Figure 8: Reaction rate of $\mathrm{CaCO}_{3}$ plotted against the HF concentration.

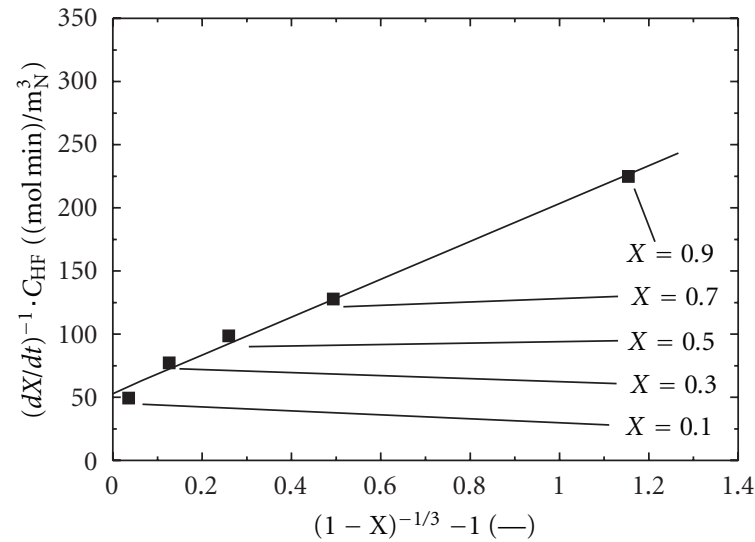

(a) Grain size: 1-2 mm

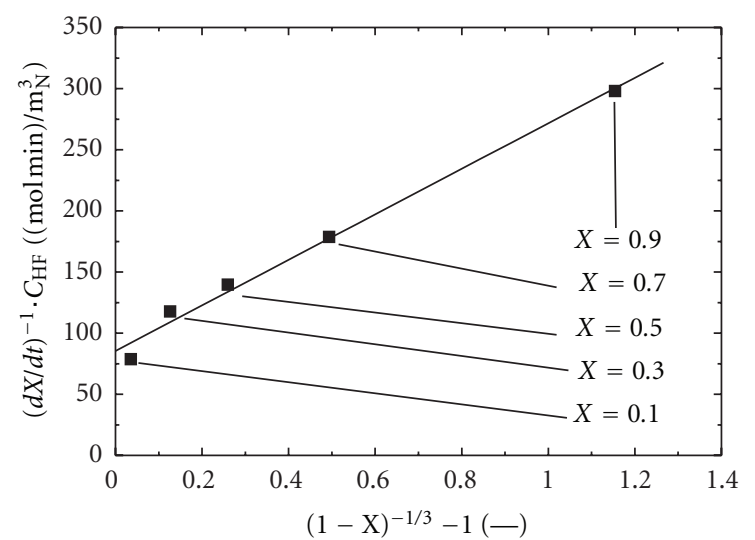

(b) Grain size: $2-5 \mathrm{~mm}$

Figure 9: Plots of $(d X / d t)^{-1} \cdot C_{\mathrm{HF}}$ versus $(1-X)^{-1 / 3}-1$

TABLE 3: Rate constants of the gas-solid reaction of $\mathrm{HF}$ and $\mathrm{CaCO}_{3}$.

\begin{tabular}{llr}
\hline Grain size $1-2 \mathrm{~mm}$ & $f_{p}=6.67 \times 10^{-3}\left[\mathrm{~m}^{3} /(\mathrm{mol} \cdot \mathrm{min})\right]$ & $f_{g}=1.88 \times 10^{-2}\left[\mathrm{~m}^{3} /(\mathrm{mol} \cdot \mathrm{min})\right]$ \\
Grain size $2-5 \mathrm{~mm}$ & $f_{p}=5.37 \times 10^{-3}\left[\mathrm{~m}^{3} /(\mathrm{mol} \cdot \mathrm{min})\right]$ & $f_{g}=1.17 \times 10^{-2}\left[\mathrm{~m}^{3} /(\mathrm{mol} \cdot \mathrm{min})\right]$ \\
\hline
\end{tabular}

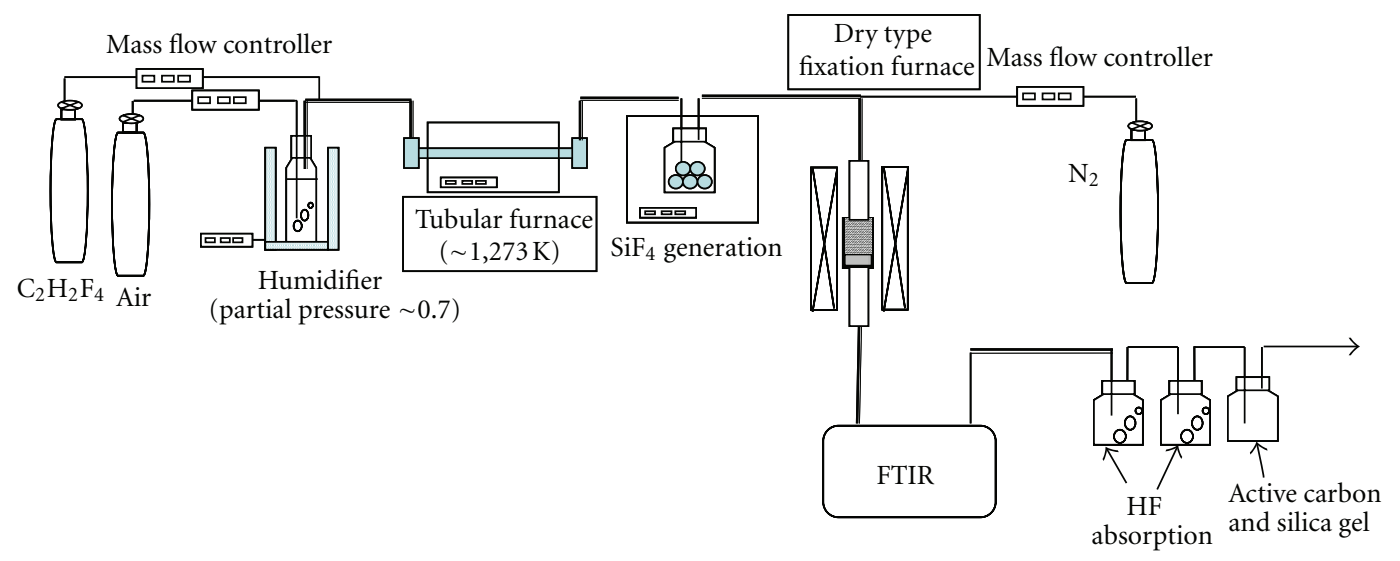

_ Temperature trace tube

FIGURE 10: Experimental flow of the gas-solid reaction of $\mathrm{SiF}_{4}$ and sodium adsorbents. 


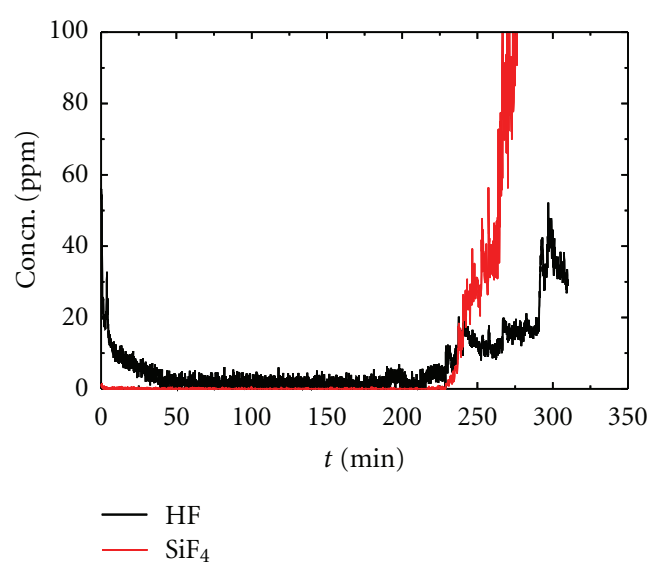

(a) $\mathrm{NHCO}_{3}$

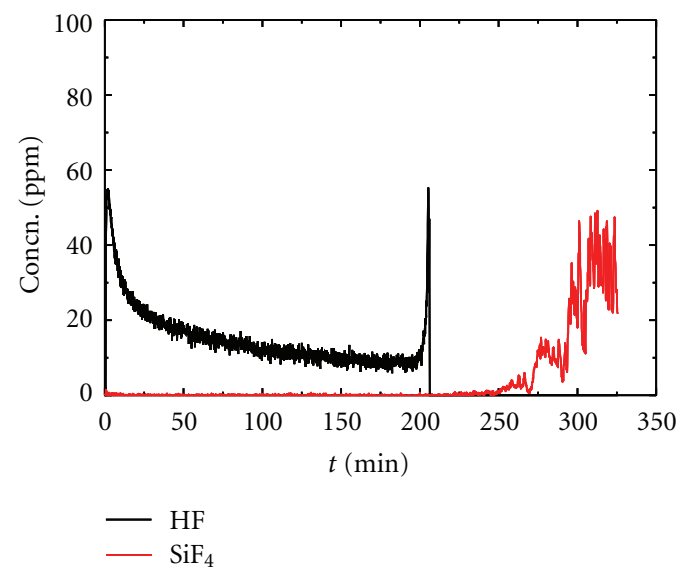

(b) $\mathrm{NaF}$

FIGURE 11: Breakthrough properties of $\mathrm{HF}$ and $\mathrm{SiF}_{4}$.

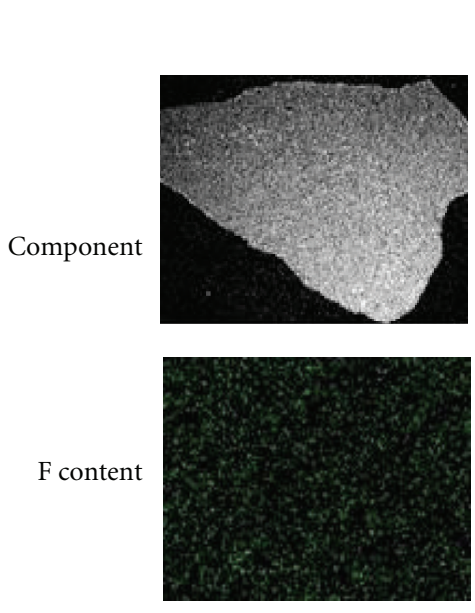

(a) Before reaction

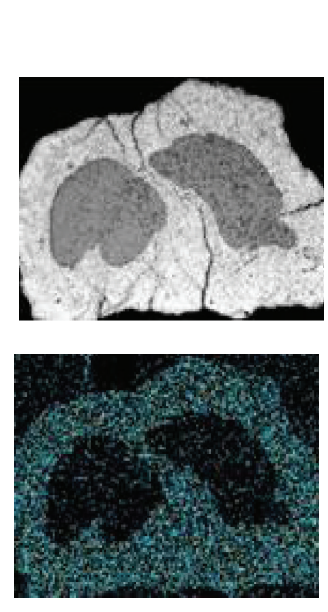

(b) During reaction
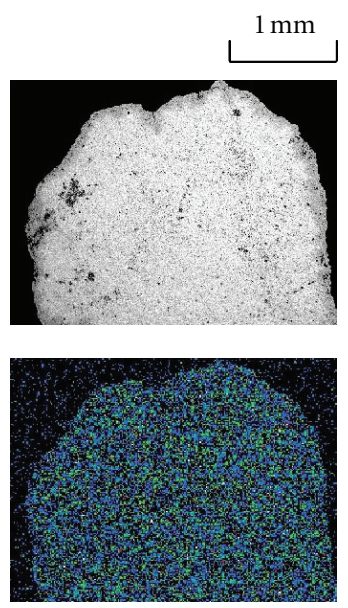

(c) After reaction

FIgURE 12: EPMA photographs of the $\mathrm{CaCO}_{3}$ adsorbents before and after experiments.

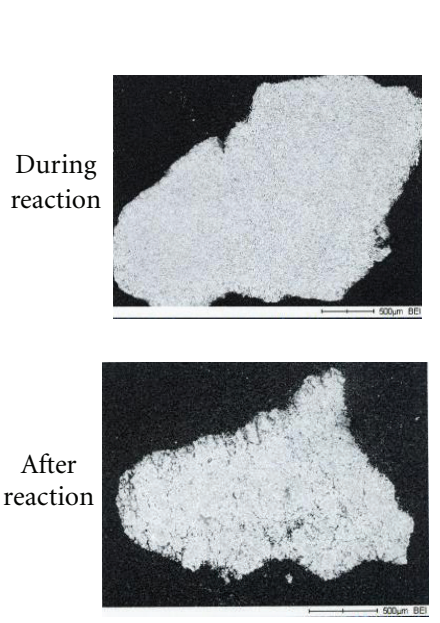

(a) Component
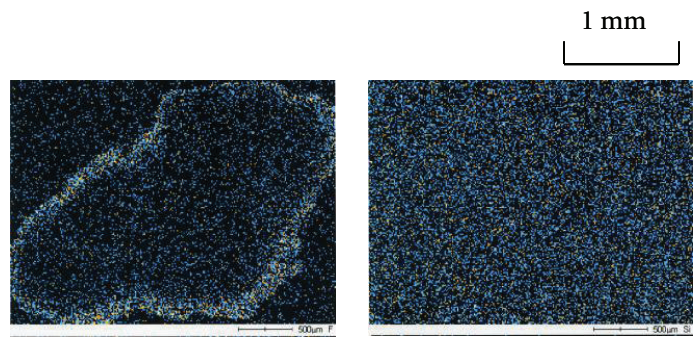

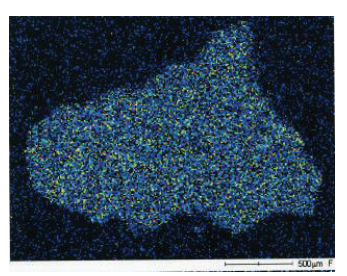

(b) F content

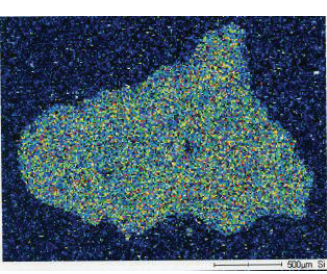

(c) Si content

FIgURE 13: EPMA photographs of the $\mathrm{NaHCO}_{3}$ adsorbents before and after experiments. 
TABLE 4: Experimental conditions of the fixed-bed furnace.

\begin{tabular}{cccccccc}
\hline & $W$ & $T$ & $V$ & $L$ & $\mathrm{~L} / \mathrm{D}$ & $v$ & $\mathrm{SV}$ \\
$\mathrm{g}$ & ${ }^{\circ} \mathrm{C}$ & $\mathrm{cm}^{3}$ & $\begin{array}{c}\mathrm{cm} \\
-\end{array}$ & $\begin{array}{c}\mathrm{cm} / \mathrm{s} \\
\mathrm{h}^{-1}\end{array}$ \\
\hline $\mathrm{NaHCO}_{3}$ or $\mathrm{NaF}$ & 12 & 150 & 10.4 & 1.68 & 0.60 & 11.7 & 25066 \\
\hline
\end{tabular}

used because it is generated by the reaction of $\mathrm{HF}$ and $\mathrm{NaHCO}_{3}$ in the fixed-bed furnace. The concentrations of $\mathrm{HF}$ and $\mathrm{SiF}_{4}$ in the exhaust gas from the fixed-bed furnace were analyzed by Fourier-transform infrared spectroscopy (FT-IR), and the amount of $\mathrm{SiF}_{4}$ adsorbed by each adsorbent up to the moment of breakthrough was determined. Table 4 shows the gas-solid reaction conditions of these experiments.

5.2. Experimental Results. Figure 11 shows the results of the breakthrough properties of each adsorbent. The breakthrough times of $\mathrm{SiF}_{4}$ in both adsorbents were more than $200 \mathrm{~min}$ from after the start of the gas-solid reaction. Because the concentration of $\mathrm{SiF}_{4}$ was less than $3 \mathrm{ppm}$, which is the TLV value of $\mathrm{SiF}_{4}$, until the breakthrough time, it was confirmed that both sodium-based adsorbents can completely adsorb $\mathrm{SiF}_{4}$. The breakthrough times for the $\mathrm{NaHCO}_{3}$ and $\mathrm{NaF}$ adsorbents were $230 \mathrm{~min}$ and $250 \mathrm{~min}$, respectively. The adsorption capacity of each adsorbent was then calculated using that obtained time to be $0.133 \mathrm{~g}-\mathrm{SiF}_{4} / \mathrm{g}$ $\mathrm{NaHCO}_{3}$ and $0.145 \mathrm{~g}_{-} \mathrm{SiF}_{4} / \mathrm{g}-\mathrm{NaF} . \mathrm{NaHCO}_{3}$ can adsorb both the $\mathrm{HF}$ and $\mathrm{SiF}_{4}$ that leak from $\mathrm{CaCO}_{3}$ layer. The amount of $\mathrm{NaHCO}_{3}$ filling the fix-bed furnace can be calculated using the obtained adsorption capacities for each gas by the amount of $\mathrm{CaCO}_{3}$ loading in the fixation furnace.

\section{Chemical Analysis of the Obtained Fluorides}

The major advantage of this dry-treatment system is the ability to recycle the obtained fluorides. This section shows the chemical properties of the obtained fluorides. Figure 12 shows the EPMA photographs of the cross-section of the calcium adsorbents before and after the reactions. It is confirmed that the reaction with fluorine proceeds to the core of the calcium adsorbent. $\mathrm{Mg}$ and $\mathrm{Si}$ impurities are detected at about several hundred or several thousand ppm in the obtained calcium fluorides. These impurities are originally contained in the raw calcium carbonate materials as dolomite $\left(\mathrm{CaMg}\left(\mathrm{CO}_{3}\right)_{2}\right)$ and silica. However, the purity of the obtained $\mathrm{CaF}_{2}$ is over $97 \%$, which is sufficient for it to be recycled as fluorine resources.

The EPMA photographs of the cross-section of the $\mathrm{NaHCO}_{3}$ adsorbents before and after the experiments are shown in Figure 13. Similar to the $\mathrm{CaCO}_{3}$ adsorbent, the fluorine and silicon reaction proceeded to the core of the adsorbents. Silicon was detected as $\mathrm{Na}_{2} \mathrm{SiF}_{6}$ by X-ray diffraction analysis. This sodium-based material can be also reused as a special material by the fluorine industry.

\section{Conclusions}

In order to develop a new dry-type gas treatment system for semiconductor facilities, the gas-solid reaction properties of $\mathrm{HF}, \mathrm{SiF}_{4}$ gas, and solid adsorbents in a fixation furnace were investigated. From the experimental results of the $\mathrm{HF}$ breakthrough properties of the $\mathrm{CaCO}_{3}$ adsorbent, the apparent gas-solid reaction rate constants were obtained by using the rate formula of the unreacted core model. In addition, the $\mathrm{HF}$ and $\mathrm{SiF}_{4}$ breakthrough properties of sodium base adsorbents of $\mathrm{NaHCO}_{3}$ and $\mathrm{NaF}$ were investigated, and the adsorption capacities of each adsorbent were obtained. From the experimental results of the gassolid reaction rate constants and the adsorption capacities, the optimum dry-type fixation furnace can be designed. Furthermore, by examining the chemical compositions of the obtained fluorides, it was confirmed that the calcium fluoride could be recycled as a fluorine resource.

\section{Acknowledgments}

This work was supported by a Grant-in-Aid for Scientific Research (C), the Iwatani Naoji Foundation's Research Grant.

\section{References}

[1] Ministry of Economy, Trade and Industry, "About the Future State of the Cure Against Discharge Control of Chlorofluorocarbon," Ministry of Economy, Trade and Industry Report, 2006.

[2] Mineral commodity summarizes, 2010, http://minerals.usgs. gov/minerals/pubs/mcs/.

[3] H. Shirai, M. Kobayashi, and M. Nunokawa, "Modeling of desulfurization reaction for fixed bed system using honeycomb type iron oxide sorbent and desulfurization characteristics in coal gas," Kagaku Kogaku Ronbunshu, vol. 27, no. 6, pp. 771778,2001

[4] C. B. Shumaker and R. Schuhmann Jr., "Reaction rates for sulfur fixation with iron at 1100 to $1275 \mathrm{~K}$," Metallurgical Transactions B, vol. 14, no. 2, pp. 291-300, 1983.

[5] S. Yasui, K. Ikeda, and H. Shirai, "Research on dry-processing technology for reconverted resources fluorine from waste chlorofluorocarbons," in Proceedings of the AIChE Annual Meeting, Salt Lake City, Utah, USA, November 2007, Paper no. $173 \mathrm{~d}$.

[6] S. Yasui, S. Nakai, A. Ueno, T. Utsumi, T. Imai, and T. Murakami:, "Low temperature dry processing technology for exhaust gases containing fluorine using calcium absorbents," in Proceedings of the 18th International Congress of Chemical and Process Engineering (CHISA '08), Prague, Czech Republic, 2008.

[7] J. Szekely, J. W. Evans, and H. Y. Sohn, Gas-Solid Reaction, Academic Press, New York, NY, USA, 1976. 

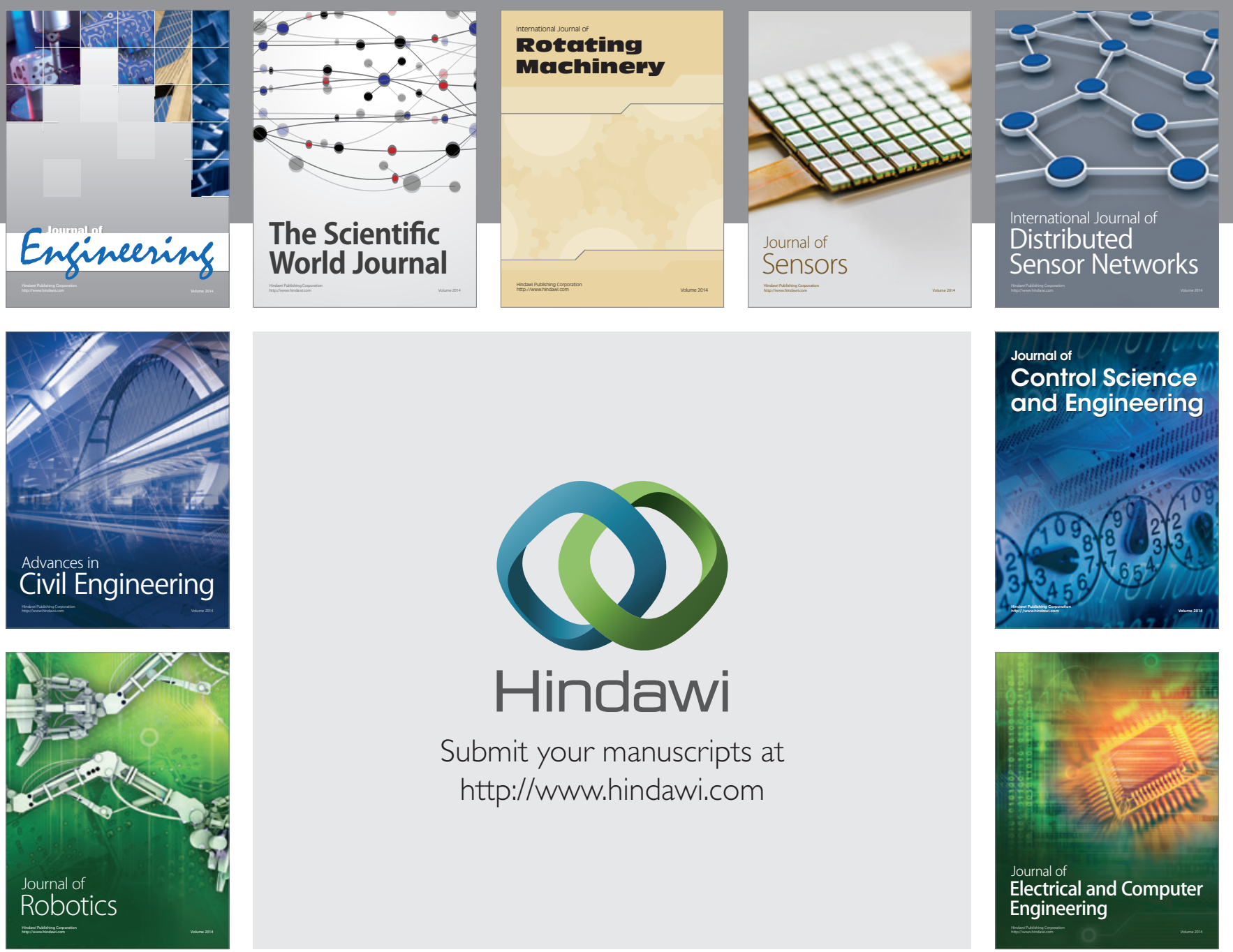

Submit your manuscripts at

http://www.hindawi.com
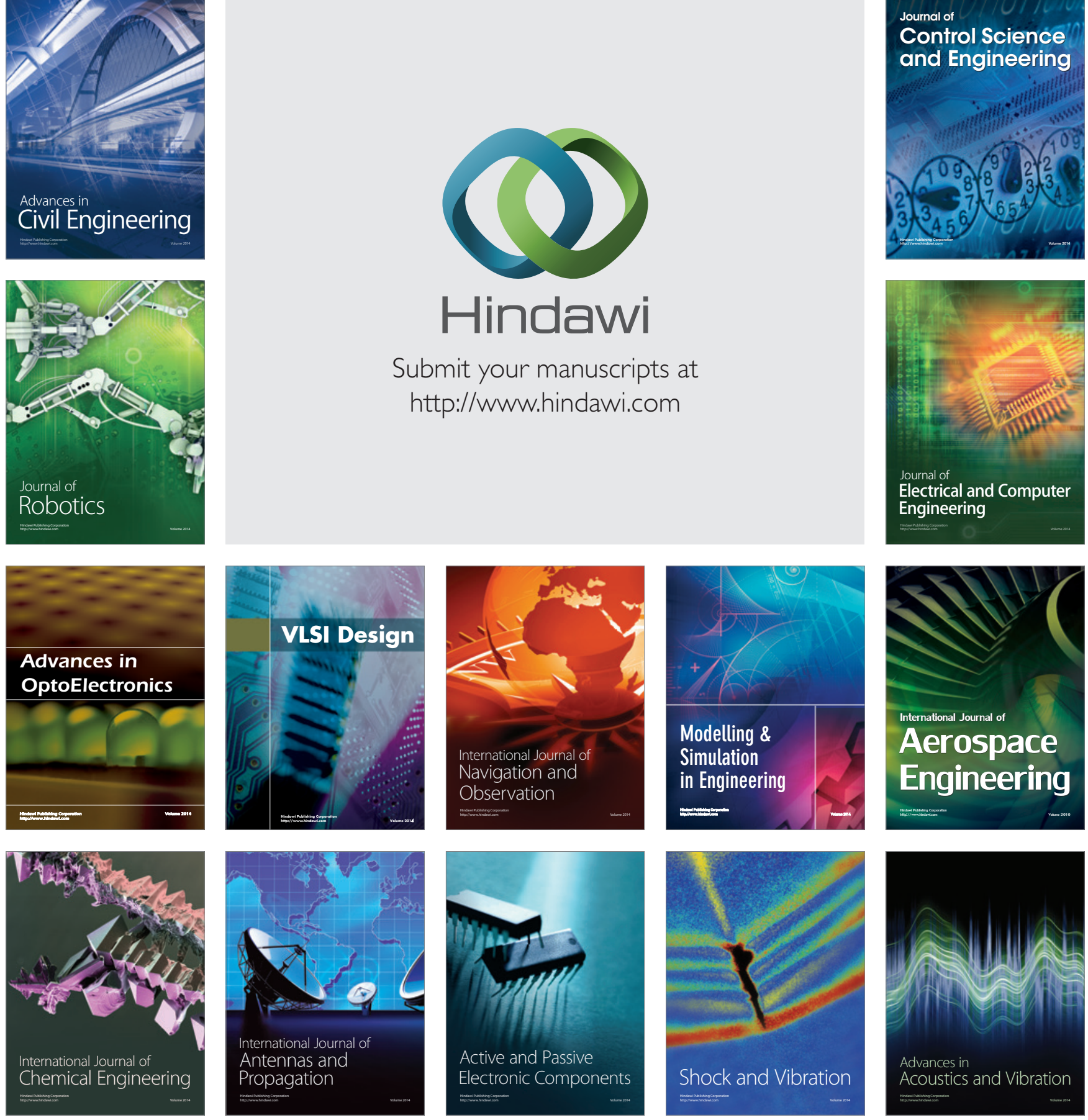